\title{
Immunolocalization of long-chain acyl-CoAs in plant cells
}

\author{
Paraskevi Diakou ${ }^{\mathrm{a}}$, Sandrine Fedou ${ }^{\mathrm{b}}$, Jean-Pierre Carde ${ }^{\mathrm{b}}$, Claude Cassagne ${ }^{\mathrm{a}, \mathrm{c}}$, \\ Patrick Moreau ${ }^{\mathrm{a}}$, Lilly Maneta-Peyret ${ }^{\mathrm{a}, *}$ \\ aa Laboratoire de Biogenèse Membranaire, Université Victor Segalen Bordeaux 2, CNRS-UMR 5544, 146 rue Léo Saignat, 33076 Bordeaux Cedex, France
baboratoire de Biologie Cellulaire et Moléculaire du Développement des Plantes, Université Bordeaux 1, IBVM/INRA, 71, avenue Edouard Bourleaux,
33883 Villenave d'Ornon Cedex, France \\ ${ }^{\mathrm{c}}$ Ecole Supérieure de Technologie des Biomolécules, Université Victor Segalen Bordeaux 2, 146 rue Léo Saignat, 33076 Bordeaux Cedex, France
}

Received 25 October 2001; received in revised form 8 February 2002; accepted 20 February 2002

\begin{abstract}
Long chain acyl-Coenzyme A esters (acyl-CoAs) are key substrates in many enzymic reactions of lipid metabolism. Due to their amphiphilic nature, the membrane localization of these molecules cannot be established by subcellular membrane fractionation and usual biochemical studies. We have developed another approach based on ultrastructural immunogold cytochemistry. To preserve the acyl-CoA membrane content, the plant material was freeze substituted and cryoembedded after short aldehyde fixation followed by quick freezing. Using Arabidopsis thaliana root cells and specific antibodies raised against acyl-CoAs, we show that acyl-CoAs are mainly localized in endoplasmic reticulum membranes. Our results demonstrate the value of cryo-methods for the accurate localization of labile metabolites in plant cells. () 2002 Elsevier Science B.V. All rights reserved.
\end{abstract}

Keywords: Acyl-CoA antibody; Endoplasmic reticulum; Freeze substitution; Immunogold labelling; Plant cell

\section{Introduction}

Long chain acyl-Coenzyme A esters (acyl-CoAs) are versatile molecules that are involved in a plethora of cellular functions. Apart from being necessary substrates for acylation reactions, acyl-CoAs have been reported to be key regulators of fatty acid metabolism and serve as regulators of various other enzyme systems, vesicle trafficking, ion channels, and ion pumps $[1,2]$. Therefore, they have been the subject of many investigations until now. Much attention has centred on the acyl-CoA content of biological tissues and but it has not concentrated on the subcellular pools of acyl-CoAs in intracellular membrane fractions. A major difficulty in estimating the acyl-CoA content of a subcellular membrane fraction is the spontaneous partition of these molecules between the membranes and the aqueous phase.

Besides biochemical investigations, significant advances in lipids have been made by immunocytochemical studies

Abbreviations: CW, cell wall; ER, endoplasmic reticulum; G, golgi apparatus; M, mitochondria; N, nucleus; PL, plastid; PM, plasma membrane

* Corresponding author. Fax: +33-556518361.

E-mail address: Lilly.Maneta-Peyret@biomemb.u-bordeaux2.fr (L. Maneta-Peyret). using antilipid antibodies [3-5]. Nevertheless, the technical problems of the immunocytochemical detection of lipids are not only due to the suitability of the probe but also to the specific prerequisites of tissue preparation. Some prerequisites such as immobilization of the antigens, maintenance of antigenicity, accessibility of the antigens and preservation of the cell structure, are common in immunocytochemistry. With regard to lipid molecules, the fixation and dehydration steps are very critical.

The effects of fixation and processing on tissue proteins have been extensively evaluated but no systematic studies on the effects of fixation techniques on lipid immunocytochemistry have been performed. The use of different fixatives may therefore lead to contradictory conclusions [5]. Osmium tetroxide is very reactive with double bonds and therefore changes the immunocytochemical reactivity of lipids [6]. Unlike proteins, most lipid molecules are not cross-linked by aldehyde fixatives and are retained in situ throughout tissue processing only by an effective stabilization of their protein environment.

Furthermore, in the absence of a chemical stabilization of lipid molecules, tissues have to be processed at very low temperature using freeze substitution and cryoembedding to minimize lipid extraction during dehydration and embedding. Improved immunolabelling of Forssman glycolipid 
was obtained by van Genderen et al. [7] on aldehyde-fixed, freeze-substituted and low-temperature embedded tissues.

The immunogold localization of amphiphilic acyl-CoA molecules was therefore undertaken on Arabidopsis thaliana roots using a low-temperature protocol previously developed on Capsicum fruit tissues [8] and isolated plastids [9]. Arabidopsis is a useful and versatile model for genetic and biochemical studies of lipid biosynthesis and function [10]. Furthermore, Arabidopsis roots cells are very suitable for the rapid fixation because of their very small diameter $(80-100 \mu \mathrm{m})$.

\section{Materials and methods}

\subsection{Plant material and chemicals}

A. thaliana cv Columbia (Brassicaceae) seeds were allowed to germinate in the dark for 7 days at $22-24{ }^{\circ} \mathrm{C}$ in a medium containing $\mathrm{KNO}_{3} 5 \mathrm{mM}, \mathrm{KH}_{2} \mathrm{PO}_{4} 2.5 \mathrm{mM}$, $\mathrm{MgSO}_{4} 2 \mathrm{mM}, \mathrm{Ca}\left(\mathrm{NO}_{3}\right)_{2} 2 \mathrm{mM}, \mathrm{Fe}-\mathrm{EDTA} 5 \mu \mathrm{M}, \mathrm{H}_{3} \mathrm{BO}_{3}$ $70 \mu \mathrm{M}, \mathrm{MnCl}_{2} 14 \mu \mathrm{M}, \mathrm{CuSO}_{4} 0.5 \mu \mathrm{M}, \mathrm{ZnSO}_{4} 1 \mu \mathrm{M}$, $\mathrm{NaMoO}_{4} 0.2 \mu \mathrm{M}, \mathrm{NaCl} 10 \mu \mathrm{M}, \mathrm{CoCl}_{2} 0.01 \mu \mathrm{M}$, sucrose $0.5 \%$, agar $0.7 \%$ at $\mathrm{pH} 5.9$.

All chemicals were purchased from Sigma (St. Louis, MO, USA).

\subsection{Tissue processing for ultrastructural immunocytochem-} istry

A. thaliana roots were briefly fixed by aldehydes and cryoprocessed according to the method developed by Rafia [8] on Capsicum tissues. Briefly, the plant material was fixed with $4 \%$ paraformaldehyde and $0.2 \%$ glutaraldehyde in $100 \mathrm{mM}$ sodium phosphate buffer ( $\mathrm{pH} \mathrm{7.2)}$ for $1 \mathrm{~h} 30 \mathrm{~min}$ at $22{ }^{\circ} \mathrm{C}$, irradiated in a microwave oven, rinsed with the buffer solution, and progressively infiltrated with buffered 1.5 M sucrose solution. Samples were then plunged with a forceps into a Dewar vessel filled with isopentane cooled by liquid nitrogen. The frozen samples were directly thrown into plastic vials containing the substitution medium (methanol with $0.5 \%$ uranyl acetate) cooled by liquid nitrogen. The freeze substitution took place in a deep freezer at -80 ${ }^{\circ} \mathrm{C}$ for 3 days, then at $-20{ }^{\circ} \mathrm{C}$ for $5 \mathrm{~h}$. After successive infiltrations with solvent/resin mixtures $(2: 1,1: 1,1: 2 \mathrm{v}: \mathrm{v})$ at $-20{ }^{\circ} \mathrm{C}$ for $48 \mathrm{~h}$, the samples were embedded in the acrylic resin London Resin Gold (London Resin, Reading, UK) as described by Cheniclet and Rafia [11]. Polymerization was performed under UV light for 5 days at $-20{ }^{\circ} \mathrm{C}$ and 2 days at room temperature.

\subsection{Immunolabelling techniques}

Ultrathin 70-nm sections were collected on Parlodioncoated 200 mesh nickel grids. Grids were first incubated with $0.1 \%$ glycine solution for $15 \mathrm{~min}$, washed in $0.1 \%$
thyroglobulin-TBS buffer and treated for $45 \mathrm{~min}$ at $25{ }^{\circ} \mathrm{C}$ with rabbit antibodies raised against acyl-CoA [12] diluted $1 / 1000$ in $0.1 \%$ thyroglobulin-TBS. Thyroglobulin was used instead of BSA to minimize background labelling. Secondary labelling of rabbit antibodies was obtained with goat anti-rabbit IgG linked to $10 \mathrm{~nm}$ gold particles (GAR 10 , Biocell, Cardiff, UK) diluted $1 / 20$ in $0.1 \%$ thyroglobulin-TBS, for $45 \mathrm{~min}$ at $25{ }^{\circ} \mathrm{C}$ and rinsed with distilled water. After staining with $2 \%$ aqueous uranyl acetate for 3 min followed by $1 \%$ lead citrate for $30 \mathrm{~s}$, the sections were visualized and photographed using a Philips CM10 electron microscope operating at $60 \mathrm{kV}$. The pictures were taken at direct magnifications of $\times 10,000-\times 28,000$.

Control experiments included the following:

- the replacement of the primary antibodies by nonimmune rabbit serum;

- the substitution of the primary antibodies for a blocking solution;

- the adsorption test. To suppress the specific labelling corresponding to the presence of acyl-CoA molecules in the sections, the immune serum was pre-adsorbed $(2 \mathrm{~h}$ at room temperature) with $10^{-3} \mathrm{M}$ 18:1-CoA. Then this serum was used as primary antibody as described above.

\subsection{Density of immunolabelling and statistical analysis}

Micrographs from immunogold-labeled cells were taken at an original magnification of $\times 21,000$. The number of gold particles was calculated according to "the point counting" method of Weibel [13]. Forty different micrographs were examined for each situation. The density of labelling was determined by counting the number of gold particles per unit of length (micrometer) of endoplasmic reticulum (ER) and per surface unit of organelles with a 1-cm-square lattice according to Cheniclet and Carde [14]. Comparison between means was made using Student's $t$-test; using Statistica software (Statsoft, Microsoft).

\section{Results}

The intracellular distribution of acyl-CoAs was investigated by immunoelectron microscopy on A. thaliana root sections after embedding in an acrylic resin. Electron microscopy was performed on the epidermal layer of the root apex, close to the meristem [15]. To obtain similar sets of observations for each experiment and comparable results between independent experiments, electron micrographs were taken on a series of six to eight epidermal cells of the epidermal layer at the same distance from the meristematic zone. At this position, the cells begin to grow after the cell division occurring in the meristem and are poorly vacuolated. The cell nucleus in the central position is the main organelle and is separated from the transverse walls by a rather narrow cytoplasmic area containing, in addition to young mitochondria and plastids, a large array of ER 
membranes either in the form of cisternae oriented along the transverse cell walls or as tubules. The observations on immunolabelled sections concerned only the transverse cytoplasmic area between the nucleus and the cell wall.

When the sections were incubated with anti acyl-CoA antibodies (Fig. 1A), most of the immunolabelling was associated with the ER membranes, sometimes as clusters of two to three gold particles. A close inspection of the labelled ER cisternae or tubules showed that the gold particles were located either inside the lumen of the cisternae, over transections of the bounding membranes, or in the cytoplasmic area in close contact with the ER elements (Fig. 2A-C). Some labelling was present over cell wall and plasma mem- brane transections as well as on mitochondria and plastid sections. In the latter case, the gold particles were mostly present close to the plastid envelope. A few gold particles were also present on the nucleus. No labelling was observed on the other organelles and cytosol. No labelling was observed with pre-immune serum.

In a second set of experiments, we attempted to examine whether all the gold particles present over the cell compartments after incubating the sections with antibodies were actually indicative of the presence of acyl-CoA molecules. Therefore, the sections were incubated with anti-acyl-CoA antibodies previously incubated with $10^{-3} \mathrm{M}$ 18:1-CoA to complex the anti acyl-CoA antibodies (Fig. 1B). Some gold
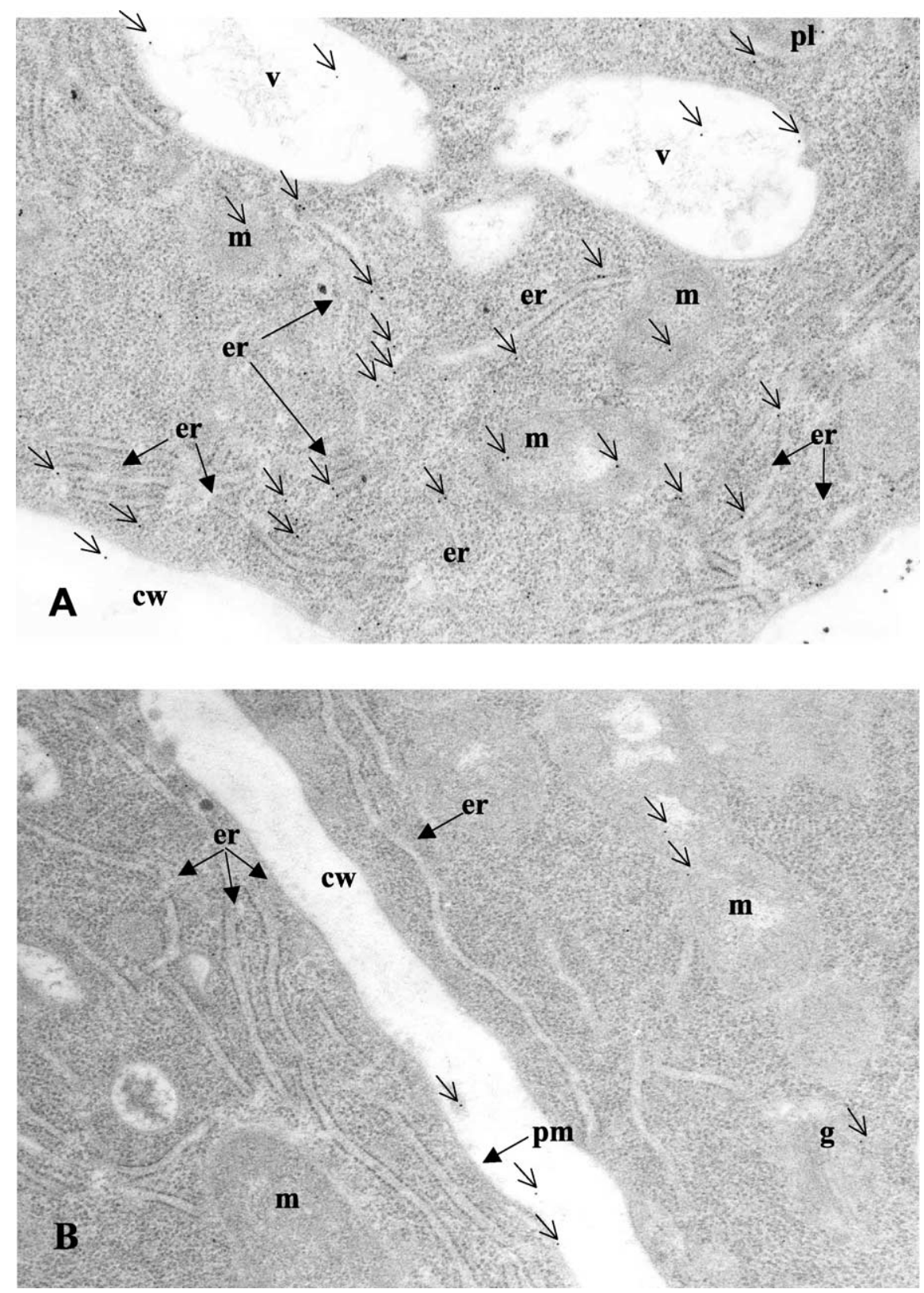

Fig. 1. Immunolabelling of Arabidopsis root cells with anti-acyl CoA antibodies (A) or pre-adsorbed acyl-CoA antibodies (B). Secondary antibodies are conjugated to $10 \mathrm{~nm}$ gold particles. (A and B: $\times 38,000$.) 

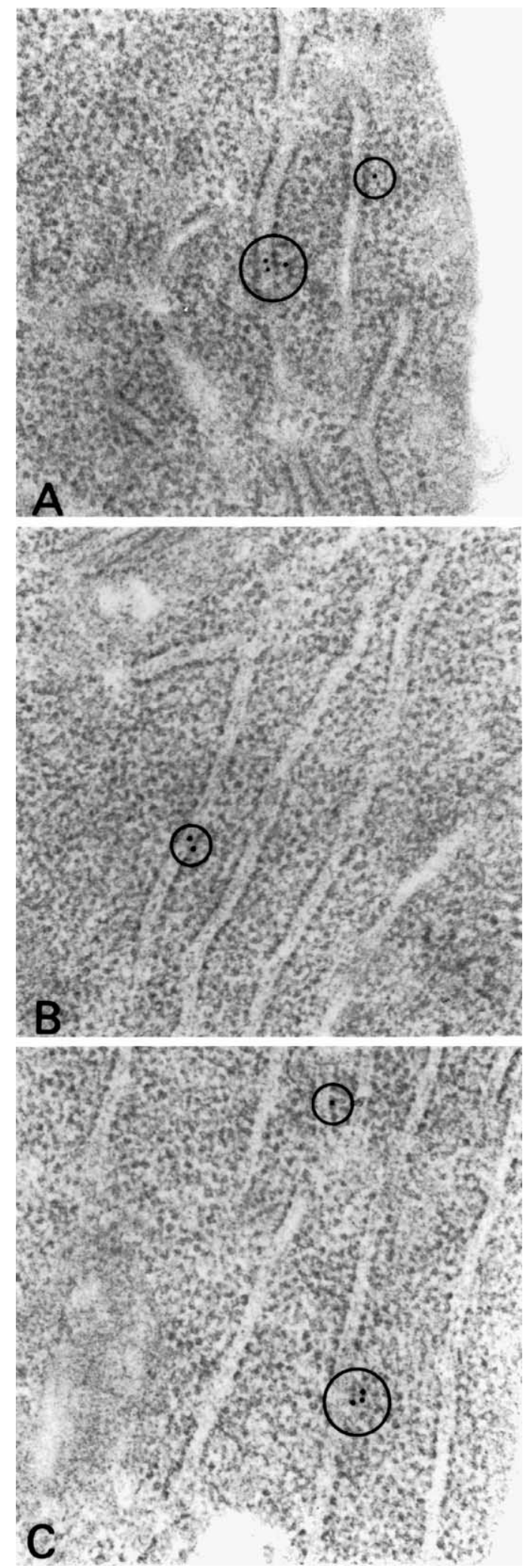

Fig. 2. Immunogold localization of acyl-CoAs in Arabidopsis root cells. Secondary antibodies are conjugated to $10 \mathrm{~nm}$ gold particles. A-C illustrate the potential localizations of the gold immunolabelling associated with the ER membranes. $(\mathrm{A}-\mathrm{C}: \times 78,000$.)
Table 1

Ratio of labelling density of epidermal Arabidopsis thaliana root cells incubated with antibodies vs. antibodies previously incubated with acylCoAs

\begin{tabular}{ll}
\hline Cell compartment & Ratio of labelling \\
\hline Endoplasmic reticulum & 3.1 \\
Mitochondria & 1.02 \\
\hline
\end{tabular}

labelling was again observed over the cell wall, the plasma membrane, the mitochondria and plastids, but at a lower density. However, the main difference concerned the ER membranes where almost no labelling was observed over any of the sections examined.

To assess whether the above mentioned differences between the antibody and the pre-adsorbed antibodies were significant, statistical analyses were performed. Table 1 presents the ER labelling ratio between cells incubated with anti-acyl CoA antibodies and cells incubated with preadsorbed acyl-CoA antibodies (immunodepleted) as well as the mitochondria ratio for the same experiments as a control. The density of labelling at the ER membrane was significantly higher in cells incubated with anti-acyl-CoA antibodies than in cells incubated with pre-adsorbed acylCoA antibodies $(P<0.05)$. On the contrary, for mitochondria, there was no significant difference of labelling between the two experiments.

The main conclusion of these experiments is that the significant decrease in gold immunolabelling of ER membranes when pre-adsorbed antibodies were used instead of antibodies, is strongly indicative of the presence of acylCoA molecules in these membranes. Acyl-CoAs are concentrated either inside the lumen of the ER tubules, within the ER membranes or in the cytoplasmic layer close to the outer side of these membranes.

\section{Discussion}

In this study, we have used immunogold labelling to localize acyl-CoAs in Arabidopsis cells freeze substituted and cryoembedded.

\subsection{Choice of processing procedure}

Adequate visualization of antigenic sites, namely acylCoA molecules, results from an optimization of the successive steps of tissue preparation. As regards tissue fixation, among the usual chemicals used as fixatives of biological tissues, osmium tetroxide is the most reactive with lipids. The fast formation of osmium dioxide with unsaturated lipids [16] allows the triglyceride-rich lipid bodies to withstand tissue processing, including ethanolic dehydration and epoxy resin embedding. However, osmium fixation is not convenient for the immunocytochemical characterization of most antigens. 
Aldehydes are also reactive with unsaturated double bonds of lipids $[17,18]$ as well as the functional groups of phospholipids, and the total amount of recoverable phospholipids decreases to a considerable extent $[6,19]$. However, their reactions with unsaturated fatty acids, which are transiently converted to 1,3-glycols and solubilized, are very slow processes occurring only in tissues fixed for extended lengths of time. The fate of acyl-CoA esters towards the step of chemical fixation of tissues remains almost totally unknown at present.

It is likely that the chemical modifications of lipids occurring at the level of unsaturated double bonds are negligible when short aldehyde fixation is used [20]. In addition, an effective cross-linking of soluble and membrane proteins leading to the stabilization of the hydrophilic environment of lipid molecules is a mandatory step in tissue processing when lipid immunocytochemistry is carried out on resin-embedded sections.

Following the observations of van Genderen et al. [7] and Oprins et al. [21], our experiments were conducted on cryoprocessed root tissues after an initial aldehydic fixation. Cryofixation/freeze substitution (CF/FS) techniques have received a considerable attention since it has proven to give better results in terms of both structural preservation and immunolabelling, when the cell water is adequately vitrified. However for plant tissues, despite the variety of fastfreezing systems developed, satisfactory results have been obtained only in a limited number of cases such as cell monolayers or meristematic or young tissues. In more differentiated tissues where vacuoles occupy a large part of the cell volume, the cooling rate decreases so rapidly from the specimen surface that ice crystal formation occurs in the bulk of the sample and that adequate cryofixation can be possibly observed only in the first micrometers [22]. Even the high-pressure freezing technique developed more recently to increase the depth of properly frozen tissue is not really convenient for direct freezing of compact, highly hydrated plant tissues (leaves, fruits...) [23]. The specific organization of plant compact assemblies of highly hydrated cells bound by semi-permeable cell walls makes immunocytochemistry difficult to deal with. The combination of paraformaldehyde fixation, cryoprotection, cryofixation and freeze substitution appears as a means to expand the possibility of obtaining high-quality immunolabelling to a large panel of plant materials and of cellular antigens and seems very convenient for lipid immunocytochemistry of plant tissues.

\subsection{Immunogold labelling}

In plant tissues, most glycerolipid synthesis occurs in ER membranes and the fatty acids used for these reactions are present as acyl-CoA thioesters. Fatty acid synthesis occurs in plastids, but in the latter, the fatty acids are esterified to an acyl carrier protein (ACP), so no acyl-CoAs are present in the plastids. For this reason, no immunolabelling was observed in the plastids. When hydrolysed, acyl-ACP esters release free fatty acids that are capable of leaving the plastidial compartment. Acyl-CoA thioesters are formed on the outer membrane of the plastid envelope, and are also found outside the plastids where they participate in the lipid synthesis within the ER. Therefore, labelling of acylCoAs could also be expected on the outer membranes of plastids. However, as pointed out by Maréchal et al. [24], acyl-CoAs have detergent properties and damaging effects in membranes, so they should rapidly be removed from the vicinity of the plastid outer envelope and transported to the ER for rapid utilization. This could explain why no labelling was observed on plastid membranes. Another reason which could explain this result is the fact that Arabidopsis is a 16:3 plant. The proportion of fatty acids exported from plastids varies according to the plant type: in 18:3 plants, most of the fatty acids are exported to the cytosol, in contrast to $16: 3$ plants that use a much larger proportion of the stromasynthesized fatty acids for their own lipid synthesis [25]. This suggests that rather few acyl-CoA molecules, if any, are present on the plastid envelope, which is in agreement with the absence of labelling observed.

In conclusion, it is the first time that acyl-CoAs are detected by an immunocytochemical method. They have been detected principally within the ER membranes, in agreement with biochemical analyses suggesting that ER is the major site of extraplastidial lipid biosynthesis. The absence of cytosolic labelling suggests that few or no acylCoAs are present in the cytosol of the tissues studied. Another question raised is the form of acyl-CoAs labeled by the antibodies: are they free or bound to other molecules? We have already shown that the anti-acyl-CoA antibodies used here recognize both free and bound acyl-CoAs [12], so all the acyl-CoA content should be labelled. However, although our antibodies were able to detect acyl-CoAs bound on proteins after SDS-PAGE, we cannot exclude that detection was made possible by the probable denaturation of proteins. Since acyl-CoA binding proteins probably have a higher affinity for acyl-CoAs than the antibodies (Hills, personal communication), acyl-CoAs bound to cytosolic acyl-CoA binding proteins might therefore be undetectable. Moreover, whether the ER labelling is due to free or bound acyl-CoAs remains to be investigated.

\section{References}

[1] N.J. Faergeman, T. Ballegaard, J. Knudsen, P.N. Black, C. DiRusso, Subcell. Biochem. 34 (2000) 175-231.

[2] N.J. Faergeman, J. Knudsen, Biochem. J. 323 (1997) 1-12.

[3] L. Maneta-Peyret, C. Freburger, J.J. Bessoule, C. Cassagne, J. Immunol. Methods 122 (1989) 123-127.

[4] A. Miyazawa, H. Inoue, T. Yoshioka, T. Horikoshi, K. Yanagisawa, M. Umeda, K. Inoue, J. Neurochem. 59 (1992) 1547-1552.

[5] A. Schwarz, A. Futerman, Biochim. Biophys. Acta 1286 (1996) $247-$ 267.

[6] L. Maneta-Peyret, P. Compère, P. Moreau, G. Goffinet, C. Cassagne, Histochem. J. 31 (1999) 541-547. 
[7] I. van Genderen, G. van Meer, J.W. Slot, H.J. Geuze, W. Voorhout, J. Cell Biol. 115 (1991) 1009-1015.

[8] F. Rafia, Thèse d'Université Biologie et Physiologie Cellulaire Bordeaux 1, Bordeaux, France, 1995.

[9] J. Pozueta-Romero, F. Rafia, G. Houlné, C. Cheniclet, J.P. Carde, M.L. Schantz, R. Schantz, Plant Physiol. 115 (1997) 1185-1194.

[10] J.G Wallis, J. Browse, Prog. Lipid Res. 41 (2002) 254-278.

[11] C. Cheniclet, F. Rafia, Rev. Fr. Histotechnol. 6 (1993) 38-47.

[12] L. Maneta-Peyret, B. Sturbois-Balcerzak, C. Cassagne, P. Moreau, Biochim. Biophys. Acta 1389 (1998) 50-56.

[13] E.R. Weibel, Int. Rev. Cytol. 26 (1969) 235-302.

[14] C. Cheniclet, J.P. Carde, Isr. J. Bot. 34 (1985) 219-238.

[15] L. Dolan, K. Janmaat, V. Willemsen, P. Linstead, S. Poethig, K. Roberts, B. Scheres, Development 119 (1993) 71-84.
[16] J.C. Riemersma, J. Histochem. Cytochem. 11 (1963) 436-442.

[17] D. Jones, Histochem. J. 1 (1969) 459-491.

[18] D. Jones, Histochem. J. 4 (1972) $421-465$.

[19] R.C. Roozemond, J. Histochem. Cytochem. 17 (1969) 482-486.

[20] R.C. Roozemond, Histochemie 20 (1969) 266-270.

[21] A. Oprins, H.J. Geuze, J.W. Slot, J. Histochem. Cytochem. 42 (1994) 497-503.

[22] D. Studer, W. Graber, A. Al-Amoudi, P. Eggli, J. Microsc. 203 (2001) 285-294.

[23] K.P. Ryan, Scanning Microsc. 6 (1992) 715-743.

[24] E. Maréchal, M. Block, A.J. Dorne, R. Douce, J. Joyard Physiol. Plant 100 (1997) 65-77.

[25] J. Browse, C. Somerville, Annu. Rev. Plant Physiol. Plant Mol. Biol. 252 (1991) 80-87. 